\title{
A study on the role of influence group in public policy making
}

\author{
Abbas Monavarian ${ }^{\mathrm{a}}$, Mojtaba Amiri ${ }^{\mathrm{b}}$ and Narges Sadat Razavimehr ${ }^{\mathrm{c}^{*}}$
}

${ }^{a}$ Associate professor, Department of Management, University of Tehran, Tehran, Iran

${ }^{b}$ Assistant professor, Department of Management, University of Tehran, Tehran, Iran

${ }^{c}$ Masters in Management, Department of Management, University of Tehran, Tehran, Iran

CHRON I C L E

Article history:

Received January 20, 2014

Accepted 5 July 2014

Available online

August 232014

Resilience

Public policy

Influence groups

Sociological association

\section{A B S T R A C T}

Nowadays, learning more about influence groups on public policy making is one of most important subjects of management science. Governments are the primary sources for public policy making but influenced groups participate indirectly and while they remain out of power, they put pressure on many decisions. Some of participants in public policy making are not influenced groups but mostly, due to their participation in policy public making matter are called influenced groups. This research, from practical research purpose and method view, is a descriptive research and survey branch. The study investigates the effect of university based Iranian Sociological Association on public policy making. The study designs a questionnaire in Likert scale and distributes it among some experts. The results of our survey indicate that that Iranian Sociological Association could influence on public policy making through elite and prominent leaders, self-knowledge and information, elective campaigns, stimulation and connecting with people and other groups.

\section{Introduction}

Sociological Associations (American Sociological Association, 1970) are normally non-profit organizations dedicated to scientific purposes in the field of sociology and social sciences (Young, 1971; Goffman, 1983; Agarwal, 1988). Perry, B., \& HArding, A. (2002) reported on two joint sessions of the British and American Sociological Associations held during the course of 2001 as a first step toward more structured dialogue and discussion between the two national associations. They presented a series of debates about the effect and future of urban sociology. It explored the challenges and opportunities given to urban sociology by increasing inter-disciplinarily and multi-disciplinary in the field of urban studies. The study also explored the role of sociology in learning the relationship between contemporary processes of globalization and urban change and the degree to which this constitutes a new dynamic core of sociological theory and research. The study also disclosed that there were a variety of alternative futures for urban sociology and there would seem to be little evidence on one specific route, nor on how to get there.

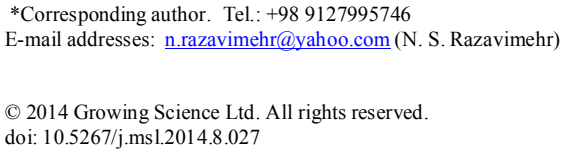




\section{The proposed study}

The study investigates the effect of university based Iranian Sociological Association on public policy making. The study designs a questionnaire in Likert scale and distributes it among some experts by aiming to measure the effects of six factors including elite and prominent leaders, existing rules and regulations, knowledge and information, elective campaigns, stimulation and connecting with people and other groups. First, we have distributed the questionnaire among 15 experts and Cronbach alpha is measured as 0.833 , which validates the overall questionnaire. The sample size is calculated as follows,

$$
n=\frac{N \times z_{\alpha / 2}^{2} \times p \times q}{\varepsilon^{2} \times(N-1)+z_{\alpha / 2}^{2} \times p \times q},
$$

where $N$ is the population size, $p=1-q$ represents the yes/no categories, $z_{\alpha / 2}$ is CDF of normal distribution and finally $\varepsilon$ is the error term. Since we have $p=0.5, z_{\alpha / 2}=1.96$ and $N=724$, the number of sample size is calculated as $n=255$. We have distributed 300 questionnaires and managed to collect 285 filled ones. The implementation of Kolmogrove-Smirnove test has confirmed that all data were normally distributed. Therefore, we use parametric test to verify the effect of mentioned factors.

\section{The results}

In this section, we present details of our findings on testing various hypotheses of the survey. We first present details of testing six hypotheses of the survey and then present the implementation of Freedman test for ranking six items.

\subsection{The results of $t$-student}

\subsubsection{The first hypothesis: The effect of elite and prominent leaders}

The first hypothesis investigates the effects of elite and prominent leaders on public policy making. Table 1 shows details of our findings.

Table 1

The summary of the effects of elite and prominent leaders

\begin{tabular}{cccccccccc}
\hline \multirow{2}{*}{ Attribute } & \multirow{2}{*}{$\mathrm{N}$} & $\mathrm{t}$ & \multirow{2}{*}{$\mathrm{df}$} & \multirow{2}{*}{ Sig. } & Std. Dev. & Mean & \multicolumn{2}{c}{$\%$ Low Confidence } \\
\hline Elite leaders & 285 & 22.57 & 284 & 0.009 & 0.42 & 0.56 & 0.51 & 0.61 \\
\hline
\end{tabular}

As we can observe from the results of Table 1, T student value is statically significant and we can confirm the first hypothesis of the survey.

\subsubsection{The second hypothesis: The effect of existing rules and regulations}

The second hypothesis investigates the effects of existing rules and regulations on public policy making. Table 2 presents details of our survey.

Table 2

The summary of the effects of existing rules and regulations

\begin{tabular}{|c|c|c|c|c|c|c|c|c|}
\hline \multirow{2}{*}{ Attribute } & \multirow{2}{*}{$\mathrm{N}$} & \multirow{2}{*}{$\mathrm{t}$} & \multirow{2}{*}{$\mathrm{df}$} & \multirow{2}{*}{ Sig. } & \multirow{2}{*}{ Std. Dev. } & \multirow{2}{*}{ Mean } & \multicolumn{2}{|c|}{$\% 95$ Confidence } \\
\hline & & & & & & & Lower & Upper \\
\hline Rules and regulation & 285 & 38.89 & 284 & 0.002 & 0.24 & 3.54 & 0.57 & 0.51 \\
\hline
\end{tabular}


As we can observe from the results of Table 2, $\mathrm{T}$ student value is statically significant and we can confirm the second hypothesis of the survey.

\subsubsection{The third hypothesis: The effect of elective campaigns}

The third hypothesis investigates the effects of elective campaigns on public policy making. Table 3 presents details of our survey.

\section{Table 3}

The summary of the effects of elective campaigns

\begin{tabular}{ccccccccc}
\hline Attribute & $\mathrm{N}$ & $\mathrm{t}$ & $\mathrm{df}$ & \multirow{2}{*}{ Sig. } & Std. Dev. & Mean & \multicolumn{2}{c}{ \%95 Confidence } \\
\cline { 7 - 9 } & & & & & & & Lower & Upper \\
\hline Rules and regulation & 285 & 38.33 & 284 & 0.0012 & 0.29 & 3.65 & 0.68 & 0.61 \\
\hline
\end{tabular}

As we can observe from the results of Table 3, T student value is statically significant and we can confirm the third hypothesis of the survey.

\subsubsection{The fourth hypothesis: The effect of existing rules and regulations}

The fourth hypothesis surveys the impacts of existing rules and regulations on public policy making. Table 4 summarizes the results of our survey.

\section{Table 4}

The summary of the effects of existing rules and regulations

\begin{tabular}{|c|c|c|c|c|c|c|c|c|}
\hline \multirow{2}{*}{ Attribute } & \multirow{2}{*}{$\mathrm{N}$} & \multirow{2}{*}{$\mathrm{t}$} & \multirow{2}{*}{ df } & \multirow{2}{*}{ Sig. } & \multirow{2}{*}{$\begin{array}{l}\text { Std. } \\
\text { Dev. }\end{array}$} & \multirow{2}{*}{ Mean } & \multicolumn{2}{|c|}{$\% 95$ Confidence } \\
\hline & & & & & & & Lower & Upper \\
\hline Existing rules and regulations & 285 & -13.57 & 284 & 0.176 & 0.99 & 0.56 & -0.19 & 0.36 \\
\hline
\end{tabular}

As we can observe from the results of Table 4, $\mathrm{T}$ student value is not statically significant and we cannot confirm the fourth hypothesis of the survey.

\subsubsection{The fifth hypothesis: The effect of elective campaigns}

The fifth hypothesis investigates the effects of elective campaigns on public policy making. Table 5 presents details of our survey.

Table 5

The summary of the effects of elective campaigns

\begin{tabular}{|c|c|c|c|c|c|c|c|c|}
\hline \multirow{2}{*}{ Attribute } & \multirow{2}{*}{$\mathrm{N}$} & \multirow{2}{*}{$\mathrm{t}$} & \multirow{2}{*}{ df } & \multirow{2}{*}{ Sig. } & \multirow{2}{*}{ Std. Dev. } & \multirow{2}{*}{ Mean } & \multicolumn{2}{|c|}{$\% 95$ Confidence } \\
\hline & & & & & & & Lower & Upper \\
\hline Stimulating people & 285 & 39.15 & 284 & 0.001 & 0.33 & 3.76 & 0.72 & 0.79 \\
\hline
\end{tabular}

As we can observe from the results of Table 5, T student value is statically significant and we can confirm the fifth hypothesis of the survey.

\subsubsection{The sixth hypothesis: The effect of existing rules and regulations}

The sixth hypothesis investigates the effects of connection with people on public policy making. Table 6 presents details of our survey. 
Table 6

The summary of the effects of connection with people

\begin{tabular}{ccccccccc}
\hline \multirow{2}{*}{ Attribute } & \multirow{2}{*}{$\mathrm{N}$} & $\mathrm{t}$ & $\mathrm{df}$ & \multirow{2}{*}{ Sig. } & Std. Dev. & Mean & \multicolumn{2}{c}{ \%95 Confidence } \\
\cline { 8 - 10 } & & & & & & & & \\
Connection with people & 285 & 42.96 & 284 & 0.003 & 0.21 & 3.52 & 0.50 & 0.55 \\
\hline
\end{tabular}

As we can observe from the results of Table 6, T student value is statically significant and we can confirm the six hypothesis of the survey.

\subsection{The results of Freedman test}

In the previous section, we have confirmed the effects of five factors on public policy making and now we find out more about the effects of these factors. Now, we present details of our implementation of Freedman test (Friedman, 1937). In our survey, stimulating the people is number one priority (mean rank $=4.44$ ) followed by election campaigns (mean rank $=3.81$ ), elite leaders (mean rank $=3.61)$, information (mean rank $=3.49)$, communication with people (mean rank $=3.29)$ and existing rules and regulations (mean rank $=2.36$ ).

\section{Conclusion}

Sociological Associations are normally non-profit organizations dedicated to scientific purposes in the field of sociology and social sciences. In this paper, we have presented an empirical investigation to study the effects of different factors on public policy making in Iranian communities. The study more concentrated on university based people who were involved in such association and using a survey questionnaire the study has detected that stimulating the people was number one important factor followed by election campaigns, elite leaders, information, communication with people and existing rules and regulations.

\section{Acknowledgement}

The authors would like to thank the anonymous referees for constructive comments on earlier version of this paper.

\section{References}

Agarwal, B. (Ed.). (1988). Structures of patriarchy: State, community and household in modernising Asia (Vol. 2). London: Zed Books.

American Sociological Association. (1970). Guide to Graduate Departments of Sociology. American Sociological Association.

Friedman, M. (1937). The use of ranks to avoid the assumption of normality implicit in the analysis of variance. Journal of the American Statistical Association, 32(200), 675-701.

Goffman, E. (1983). The interaction order: American Sociological Association, 1982 presidential address. American Sociological Review, 48(1), 1-17.

Perry, B., \& HArding, A. (2002). The future of urban sociology: report of joint sessions of the British and American Sociological Associations. International Journal of Urban and Regional Research, 26(4), 844-853.

Young, M. F. (Ed.). (1971). Knowledge and control: New directions for the sociology of education. 